\title{
Challenges and Opportunities in Global Mental Health: a Research-to-Practice Perspective
}

\author{
Milton L. Wainberg ${ }^{1}$, Pamela Scorza ${ }^{1}$, James M. Shultz ${ }^{2}$, Liat Helpman ${ }^{1}$, Jennifer J. Mootz ${ }^{1}$, \\ Karen A. Johnson ${ }^{1}$, Yuval Neria ${ }^{1}$, Jean-Marie E. Bradford ${ }^{1}$, Maria A. Oquendo ${ }^{3}$, and Melissa \\ R. Arbuckle ${ }^{1}$ \\ ${ }^{1}$ Department of Psychiatry, Columbia University Medical Center and New York State Psychiatric \\ Institute, 1051 Riverside Drive, Unit 24, New York, NY 10032, USA \\ ${ }^{2}$ Center for Disaster and Extreme Event Preparedness (DEEP Center), University of Miami Miller \\ School of Medicine, Miami, FL 33160, USA \\ ${ }^{3}$ Department of Psychiatry, University of Pennsylvania Perelman School of Medicine, 3535 Market \\ Street, Suite 200, Philadelphia, PA 19104-3309, USA
}

\begin{abstract}
Purpose of Review-Globally, the majority of those who need mental health care worldwide lack access to high-quality mental health services. Stigma, human resource shortages, fragmented service delivery models, and lack of research capacity for implementation and policy change contribute to the current mental health treatment gap. In this review, we describe how health systems in low- and middle-income countries (LMICs) are addressing the mental health gap and further identify challenges and priority areas for future research.
\end{abstract}

Recent Findings-Common mental disorders are responsible for the largest proportion of the global burden of disease; yet, there is sound evidence that these disorders, as well as severe mental disorders, can be successfully treated using evidence-based interventions delivered by trained lay health workers in low-resource community or primary care settings. Stigma is a barrier to service uptake. Prevention, though necessary to address the mental health gap, has not solidified as a research or programmatic focus. Research-to-practice implementation studies are required to inform policies and scale-up services.

Summary-Four priority areas are identified for focused attention to diminish the mental health treatment gap and to improve access to high-quality mental health services globally: diminishing pervasive stigma, building mental health system treatment and research capacity, implementing prevention programs to decrease the incidence of mental disorders, and establishing sustainable scale up of public health systems to improve access to mental health treatment using evidencebased interventions.

Compliance with Ethical Standards

Conflict of Interest Milton L. Wainberg, Pamela Scorza, James M. Shultz, Liat Helpman, Jennifer J. Mootz, Karen A. Johnson, Yuval Neria, Jean-Marie E. Bradford, and Melissa R. Arbuckle declare that they have no conflict of interest.

Maria A. Oquendo's family owns stock in Bristol Myers Squibb. Dr. Oquendo receives royalties for the commercial use of the Columbia Suicide Severity Rating Scale.

Human and Animal Rights and Informed Consent This article does not contain any studies with human or animal subjects performed by any of the authors. 


\section{Keywords}

Global mental health; Implementation science; Task-sharing; Low- and middle-income countries; Primary care

\section{Introduction}

Mental and substance use disorders are now the leading cause of disability worldwide [1]. This documented global burden of disease associated with mental disorders [2] is compounded by the widening "mental health treatment gap" where, worldwide, more than $70 \%$ of persons who need mental health services lack access to care [3]. Paradoxically, this gap exists at a time when evidence-based mental health interventions have been found to be effective in limited resource environments $[4 \bullet, 5]$. Trials conducted in low- and middleincome countries (LMICs) have demonstrated the efficacy and effectiveness of both psychopharmacological treatment and evidence-based psychotherapies for treating mental disorders [6-13]. Furthermore, studies on the cost-effectiveness of mental health treatments increasingly highlight the economic value of preventing and treating mental disorders in these settings $[14 \bullet \bullet, 15]$.

To help decrease the global mental health (GMH) treatment gap, the World Health Organization (WHO) developed the Mental Health Gap Action Programme Intervention Guide (mhGAP-IG) through a systematic review of evidence followed by an international participatory consultative process. The mhGAP-IG comprises straightforward, user-friendly, diagnosis-specific clinical guidelines for providing evidence-based practices (EBPs). The guidelines are meant to be used by non-specialized health care providers after adaptation for national and local needs [16].

Despite the existence of these guidelines, dissemination and implementation of EBPs and translation of scientific findings into health policy have been lagging in LMICs [17]. Interrelated challenges that contribute to these deficiencies and also exacerbate the GMH treatment gap include shortages of mental health workers, lack of research capacity, stigmatization of mental illness, and the siloing of mental health services apart from other health services for physical health conditions.

Capacity building for mental health services and research in LMICs represents an urgent need that has so far failed to attract sufficient attention and funding [18, 19]. Implementation research is now required to understand how best to integrate and sustain mental health services within health systems and other contexts of care [20]. In this review, we outline the current state of research addressing mental health within health systems in LMICs. We then discuss four priority areas of focus for future GMH research to address the mental health gap.

\section{Integrating Treatment of Common Mental Disorders in Primary Care}

Until recently, in most LMICs and low-resource settings within high-income countries (HICs), mental disorders have typically been diagnosed and treated in centralized psychiatric 
hospitals or clinics. Services for mental health diagnosis, treatment, and referral that are based in primary care or community health centers are generally lacking [21]. In this context, people with severe mental illnesses who live far from a centralized treatment facility - the majority of the population in most LMICs—are often unable to access care, and people with common mental disorders such as major depression, generalized anxiety disorder, and substance use disorders, persons who collectively account for more than half of the total GMH burden globally, are most often left untreated [1].

In an effort to expand the coverage of mental health services, countries around the world have been moving towards community mental health care. A series of articles in World Psychiatry describe the successes and challenges that regions around the world have faced in integrating community mental health services in primary care [11-13, 22-24]. Many countries have made significant strides in legislating mental health reform and in moving toward de-institutionalization. However, generally, mental health services in the community have not been prepared to face the resulting mental health care needs. Challenges to integrating mental health care into primary health care within LMICs include limited infrastructure; shortages of human resources; limited community awareness of mental health; poverty and social deprivation; high rates of comorbidity with physical health problems; high levels of stigma and discrimination against people living with mental illnesses; and different explanatory models for mental health conditions, which influence the acceptability and uptake of services [21, 25, 26]. Despite these complex and interconnected challenges, research is advancing on how to best integrate mental health into primary care in LMICs [27].

In 2013, the World Health Assembly adopted the Comprehensive Mental Health Action Plan for 2013-2020 [28], which committed the United Nations (UN) member states to provide mental health care that is integrated into primary care and subsumes both common and severe mental disorders. Thus, UN member states have committed to transforming their community-based primary health care systems to include diagnosis and treatment of both severe mental illness and common mental disorders, as well as mental health promotion and prevention.

The "Programme for Improving Mental health carE" (PRIME), funded by the UK government's Department for International Development (DFID), is a consortium of research institutions and Ministries of Health in five LMICs in Asia and Africa (Ethiopia, India, Nepal, South Africa, and Uganda). PRIME provides useful examples of the design, evaluation, and cost-measurement methodologies for integrating mental health treatment for priority mental disorders into primary and maternal health care contexts [10, 29•]. Several best practices have been identified, and these include customizing mental health services to the specific health system; identifying human resources available for mental health screening, referral, and treatment; and applying the principles of collaborative care and quality improvement [30].

Studies in HICs indicate that treating mental disorders and other non-communicable diseases (NCDs) together, using integrated services models (e.g., Collaborative Care), is more effective [31] and cost-effective [32] than treating co-morbid conditions separately. 
However, few studies in LMICs have gone beyond efficacy testing to examine the effectiveness of integrating depression treatment into primary care [5, 6]. Moreover, almost none of these innovations has been scaled up to benefit large populations or to reach broad geographic areas in LMICs. While most efforts around integration of mental health services in LMICs have focused on general primary care, including routine screening and basic treatments provided by doctors and nurses [33,34], mental health services also need to be integrated into specialized services for other chronic NCDs, as well as HIV/AIDS [35, 36]. Common mental disorders often co-occur with chronic illnesses, such as diabetes [37], heart disease [38], and cancer [39]. Major modifiable risk factors for NCDs, such as poor diet, physical inactivity, and tobacco use, are exacerbated by poor mental health [40], and mental illness increases the chances of poorer outcomes from chronic illnesses [41]. The rates of common mental disorders are highest among those with TB and/or HIV illness and are associated with higher morbidity and mortality, increased community transmission, drug resistance to prescribed antibiotics, and poor adherence to antiretroviral therapies [22, 24].

One notable exception is Chile's health reform policy, the Regime of Explicit Health Guarantees, which includes the National Depression Treatment Program [42]. Psychologists and general practitioners work in tandem, supplemented by specialists, to provide psychopharmacological therapy and psychosocial interventions for patients who are diagnosed with diabetes, hypertension, and depression [42]. Similar integrated NCD programs need to be developed and evaluated in other LMICs. Several initiatives have successfully integrated mental health care into maternal and child health services [43, 44], an area that has important implications for preventing mental disorders. However, as an important caveat, these promising interventions have not been disseminated or scaled up for adoption at the national health policy level, posing a significant obstacle for the long-term impact of global mental health $(\mathrm{GMH})$ research.

\section{Community Treatment of Severe and Persistent Mental IIIness}

While common mental disorders have been the focus of recent GMH research in LMICs, due to the associated public health burden, research is also needed to determine how best to address the treatment gap for serious mental illnesses, such as psychotic disorders. More than 26 million people worldwide are diagnosed with severe mental illness, with psychotic disorders ranking fifth among men and sixth among women as a leading cause of years lived with disability [45]. On average, nearly $90 \%$ of individuals requiring treatment for schizophrenia in low-income countries do not receive treatment [45]. Untreated schizophrenia places a heavy demand on caregivers [46] and often results in severe human rights violations against individuals with schizophrenia. Inpatient mental health care, provided in general hospitals or free-standing mental hospitals, contributes only modestly to meeting the overall needs for treatment access [47]. Specialized mental health services alone, even if community based, are unable to cope with the burden of severe mental illness in LMICs; primary care services should fill this gap by delivering effective packages of care in collaboration with specialized services [45].

A robust body of evidence shows that schizophrenia can be effectively treated in LMICs with typical or atypical antipsychotic drugs and psychosocial interventions, including 
assertive community treatment, supported employment, cognitive behavioral therapy, family-based services, and skills training [48]. Still, while the effectiveness of interventions for schizophrenia in LMICs is evident, implementation research is needed on how interventions can be integrated into existing services, including attention to human resource constraints and insurance coverage [49•]. For example, Asher et al. (e.g., [50]) piloted an intervention for community-based rehabilitation in Ethiopia, and a collaborative study in Brazil and Chile is now examining the implementation of the Critical Time Intervention delivered by lay health workers [51]. Additional research on early intervention for schizophrenia in LMICs is needed [52], and, similar to research addressing common mental disorders, greater efforts are necessary to link research with policy-making such that EBPs are adopted and scaled up.

\section{Stigma}

There is strong evidence suggesting that factors that delay or prevent mental illness treatment include low levels of knowledge regarding mental illness and prejudice and discrimination against people with mental illness [53]. A systematic review of effective interventions to reduce mental-health-related stigma and discrimination found that most of the research has taken place in HICs $(n=69)$, with few studies $(n=11)$ conducted in middle-income countries and none in LMICs [7]. Findings were similar to another overview [54•] describing that most research has examined short-term outcomes demonstrating improvement in positive attitudes; however, these were not associated with knowledge changes or social contact (direct or indirect) with a person with mental illness [7, 54•]. Even though some group-level anti-stigma inventions show promise, there is a need for rigorous studies with larger samples and longer-term follow-up assessments. These studies should focus on service users' perspectives on stigma and discrimination as well as behavioral change around mental health stigma [7, 54•].

\section{Prevention of Mental Disorders}

Given the magnitude of the burden of mental disorders, treatment alone will be insufficient to close the mental health gap in LMICs; yet, mental health promotion and prevention of mental illness are nascent in most LMIC health systems. One promising area of prevention includes focusing on the mental health of children. Research shows that the average age of onset of mental disorders is in childhood and adolescence. Undetected and untreated mental disorders occurring early in life lead to lifelong disability and to early, preventable death [55]. Thus, attention to child mental health should be seen as a way to prevent mental disorders in adults.

Child Mental Health as Prevention of Mental Disorders-A review of the prevalence of mental disorders found that $14 \%$ of children worldwide are estimated to suffer from a mental disorder [56]. In many LMICs, children constitute roughly $50 \%$ of the population; yet, most research on mental health interventions for children comes from HICs [57]. This discrepancy is especially apparent in the literature on mental health services for infants and primary-school children [58•, 59]. Klasen and Crombag [57] reviewed 54 randomized controlled trials (RCTs) of mental health treatments for youth in LMICs and found that none of the interventions targeted mood (depression, anxiety) or obsessive 
compulsive disorders outside of the context of traumatic experiences. Instead, interventions focused on behavioral disorders, developmental disorders, and disorders related to exposure to interpersonal violence. More recently, several epidemiological and intervention studies have been conducted with youth exposed to various forms of interpersonal violence [60], and results underscore the efficacy of group-based trauma-focused cognitive behavioral therapy (TF-CBT) for reducing posttraumatic stress symptoms [61, 62]. School interventions to prevent or to treat mental illness are common in HICs [8] and middle-income countries [9], but these efforts are lacking in LMICs, in spite of schools being an ideal setting to intervene [63].

The United Nations Children's Fund (UNICEF) estimates that six-in-ten children worldwide, ages 2-14 (almost 1 billion), experience regular physical punishment, and about seven-in-ten children experience psychological aggression [64]. Similar to research findings from HICs, childhood sexual abuse is under-reported in LMICs and has serious implications for mental health across the lifespan [65]. A recent study by the US Centers for Disease Control and Prevention (CDC) and UNICEF, in partnership with host country governments, communities, and academic institutions, examined violence against children in seven LMICs and found that more than $25 \%$ of girls and more than $10 \%$ of boys reported exposure to childhood sexual violence [66]. Data from HICs and LMICs [67] document that persons exposed to childhood sexual abuse have much higher rates of depression, anxiety, and suicidal behavior. Consequences of child maltreatment often persist into adulthood, including long-term changes in brain structure, mental and physical health problems, engagement in risky behaviors, problems with social functioning, and reduced life expectancy [68]. Therefore, programs aimed at mitigating childhood trauma and reducing violence against children constitute an important, under-recognized contribution to reducing the mental health gap globally. Developing integrated mental health services for children within primary care is a high priority for global mental health $[69,70]$.

Women's Mental Health as Prevention of Mental Disorders-Focusing on women's mental health is another under-recognized component of a strategy for preventing mental disorders. In a longitudinal study in the USA, children of women with depression were found to be five times more likely to develop depression across the course of their lives, compared to children of women without depression [71]. The relationship between maternal mental health and children's health and development has been repeatedly demonstrated, in both HICs and LMICs, and this relationship involves both psychosocial and biological pathways [72•,73]. Therefore, effective mental health interventions provided for mothers during the perinatal period could potentially prevent the onset of common mental disorders in these mothers and ultimately influence the mental health trajectories for their offspring into the next generation [72•,74]. While additional research on the mechanisms of intergenerational transmission of mental problems in LMICs is needed [72•], several interventions for peri-natal mental health have shown effectiveness in LMICs [75], including a cognitive behavioral therapy-based intervention designed to be delivered by lay health workers within community-based maternal and child health services [76•]. This intervention, Thinking Healthy, has since been scaled up in Pakistan and was adopted as the 
first in the WHO's series of "low intensity psychological interventions" recommended for use in member countries [77].

Decreasing Discrimination as Prevention of Mental Disorders-Decreasing structural inequality, stigma, and discrimination is another important form of prevention of mental disorders. Gender inequality is often more pronounced in LMICs, where women have fewer legal protections, often lack rights to land ownership, and are awarded less decision-making power in the household, reproductively and otherwise. As such, women are subjected to gender-based violence, and specifically intimate partner violence. While women overall accrue lower rates of traumatic exposure than do men, these exposures are more likely to be interpersonal, particularly sexual, in nature, heightening the risk for mental health impact. Modifying cultural norms to accomplish gender equality, albeit complex, has successfully decreased intimate partner violence and improved health outcomes, e.g., HIV incidence [64]. Similar studies addressing mental health outcomes are needed. Similarly, forced migrants (including both refugees and internally displaced persons) represent another population where trauma and inequality are the norm. Much of the research with forced migrants takes place in HICs, despite figures showing that LMICs hosted $86 \%$ of forced migrants in 2015.

Collins et al. [26] highlighted another example where prevention should be implemented to decrease mental illness among lesbian, gay, bisexual, and transgender (LGBT) persons, by modifying social risk factors, including institutional prejudice, stigma, and discrimination against LGBT individuals as a chief priority for intervention [26]. Globally, members of the LGBT community are subjected to institutionalized prejudice, social stress, social and family exclusion, anti-LGBT hatred, and violence, in addition to an internalized sense of shame about their sexuality and/or identity. Childhood abuse (sexual, physical, and emotional abuse) and sexual victimization rates during adulthood are higher among LGBT persons than among heterosexual men and women $[78,79]$. Same-sex sexual behavior is illegal in 76 countries, and in at least 10 countries, it is punishable by death [80].

Institutional prejudice, stigma, discrimination, childhood abuse, and sexual victimization of LGBT individuals may account for some of their excess risk for poor adult health and mental health outcomes [78, 81]. As such, the WHO defines sexual orientation and identity as a social determinant of health and mental health [82]. Research conducted mostly in HICs shows that LGBT persons are subjected to health inequalities and thus have higher rates of mental disorders, substance misuse and dependence, suicidal ideation, and suicide attempts and deaths, compared to their heterosexual counterparts [83]. Specifically, the results of a meta-analysis of studies conducted in HICs demonstrate a two-fold excess in risk for suicide attempts in the preceding year for LGBT men and women and a fourfold excess risk for gay and bisexual men over a lifetime [83]. Similarly, depression, anxiety, and alcohol and substance misuse were at least 1.5 times more common in LGBT individuals. Lesbian and bisexual women were at particular risk of substance dependence. Data from LMICs is scarce, and it is often unethical to conduct research with LGBT persons due to societal attitudes and the punitive policies in many LMICs [84]; yet, the few available studies confirm that negative treatment by family members predicts mental and substance use disorders $[85,86]$. 


\section{Priority Areas for Research}

As is evident above, significant challenges remain in order to close the mental health treatment gap and to make serious strides toward improving mental health globally. We highlight four specific barriers that require particular attention:

\section{Capacity-Building}

One of the most significant challenges in bridging the mental health treatment gap is the glaring shortage of trained mental health workers in health care systems worldwide [87, 88]. This dearth of credentialed mental health professionals, specifically those who are knowledgeable and highly skilled in the application of EBPs, is experienced globally and universally. No mechanisms exist currently to rapidly fill this void.

To address this critical deficit, "task-sharing"-transferring clinical duties to trained lay health workers-has emerged as a promising strategy to deal with the mental health personnel shortage [33, 89-92]. Initially described as "task shifting," the current and preferred term, "task sharing," emphasizes the need for a significant, ongoing role for psychiatrists and psychologists, including continuing supervision, quality assurance, and support for the non-specialist health workers. Several key studies have proven that lay health workers can provide effective treatment for common mental disorders in community settings in LMICs as evidenced by trials evaluating the effectiveness of interpersonal psychotherapy in Uganda and cognitive behavioral therapy in Pakistan [4•, 5, 93]. However, despite the apparent promise that task sharing holds for increasing access to mental health treatment by bolstering the personnel capacity of the health system, the ability to scale up and sustain the task-sharing model remains untested [94*0]. Task-sharing models require additional evaluation and implementation research to fine-tune the training of lay health workers, perfect the supervisory process, and optimize the division of tasks [95•].

Capacity-building must focus not only on clinicians but also on researchers. The lack of trained mental health researchers who are actively conducting studies in LMICs also limits progress. Local research is needed to adapt and evaluate interventions and services for specific contexts [96]. A new generation of researchers must be recruited and trained in a variety of skills including epidemiological and implementation research methods, knowledge translation and exchange, leadership, mentorship, and advocacy [97]. One example of such a capacity-building initiative is the US National Institute of Mental Health Collaborative Hubs for International Research on Mental Health [47]. Currently, the program sponsors five geographically distributed NIMH-funded centers, each located in an LMIC. The program aims to provide the knowledge and tools to increase research capacity in LMICs. Such collaborative capacity-building initiatives should be expanded, and training in GMH research methods should focus on hybrid designs that assess both effectiveness and implementation processes, in order to advance knowledge on how effective interventions can best be carried out in diverse environments. Implementation questions include processes for adapting interventions for specific locations, division of tasks, training, supervision, fidelity of design and implementation, and participant retention and follow-up [57, 98••, 99]. 


\section{Reducing Mental IIIness Stigma}

Identified as one of the most significant barriers to reducing the mental health treatment gap globally, mental illness stigma feeds a negative spiral of silence and suffering that leads to successive cycles of stigma and discrimination [54•]. Social exclusion, grounded on stigma, leads to poor recovery outcomes and quality of life for those suffering from mental disorders [100]. Stigma also prevents many individuals from seeking mental health services during the early stages of their disorders. Stigma-based delays in care-seeking worsen the prognosis and perpetuate the misperception that mental illnesses are beyond cure [53, 101]. Prevalent, population-wide stigma may also diminish the prestige accorded to the mental health professions, leading fewer young persons to select these specialties and thereby exacerbating the human resource shortage [33].

The literature includes few intervention studies related to stigma education in LMICs, and none are longitudinal or address behavior change around discrimination [102]. Current evidence is insufficient to determine what interventions are effective and feasible for decreasing stigma in LMICs, how best to target key groups such as health care staff, and how to adapt such interventions in specific contexts. Research around interventions to address stigma is therefore a programmatic priority.

\section{An Integrated Framework for Prevention of Mental Disorders}

Prevention of mental disorders has received little attention thus far in the field of GMH, but increasingly, researchers are realizing that prevention is key [103]. GMH experts specifically prioritized prevention as one of the "Grand Challenges" in the field. The Grand Challenge program requests proposals for research and demonstration projects to advance knowledge for effective prevention and early intervention for mental and behavioral disorders [26]. Still, research seeking to achieve early detection of mental disorders and to better understand and interrupt the process that leads from healthy mental and psychosocial functioning to mental disorders is nascent in LMICs. Existing programs in child mental health and maternal mental health could be recognized and studied as components of a strategy for preventing mental illness. Targeting vulnerable groups such as LGBT individuals could be another component of an overall prevention strategy.

\section{Scale-Up, Sustainability, and Policy}

LMICs are primed and ready for the implementation and scale-up of EBPs, including psychotherapeutic and psycho-pharmacologic treatments. However, most of the mental health efficacy, effectiveness, and implementation trials have focused narrowly on testing treatments for a single diagnosis (e.g., depression) or a small number of common mental disorders, regardless of whether the studies were conducted in LMICs or HICs $[6,8,11]$. Yet, most systems of care worldwide must provide treatment for every patient, across the full spectrum of mental health diagnoses. Thus, it is essential that we build research capacity [97] for rigorous dissemination, implementation, and policy research to determine the following: [1] the best delivery pathways for comprehensive community mental health care; [2] how best to bring these interventions to scale; and [3] how to leverage locally generated research to develop and test policies to sustain new, resource-effective systems of mental health care. To inform policies, research must consider the cost-effectiveness of treating 
mental disorders [104], the cost of implementing and scaling up care [105•], and the economic and health benefits gained by scaling up treatment [14*0]. Thus, the prime goal is to identify policy change needed to sustain optimal delivery strategies in order to decrease the GMH treatment gap, lessen the burden of mental illness in LMICs, and guarantee the human rights of people living with mental illness.

\section{Conclusion}

GMH is at a turning point. To this point, mental health has received an inadequate proportion of health funding, in comparison to the burden it causes [26]. However, two significant events in 2016 signal a shift in the international development community and a commitment to address mental health globally: (1) The World Bank endorsed mental health as a global development priority and (2) unlike the Millennium Developmental Goals, mental health was explicitly included in the Sustainable Development Goals, the United Nation's development agenda that will guide global and national agendas for the next 15 years. These two events create a unique window of opportunity to work across sectors to increase mental health funding, research, and capacity-building programs. Capacity building for researchers, clinicians, and policy makers is needed to overcome the barriers to preventing and treating all mental disorders in low-resource settings. Research has been accelerating over the past 20 years, and, while significant challenges remain, the field is well positioned to take advantage of this unique global policy moment for mental health and to develop research to practice opportunities in order to reduce the GMH research and treatment gap. GMH research needs to consistently link with policy-making so that evidence-based mental health programs are adopted and scaled-up within existing country health, educational, and other public systems. LMICs must examine how best to implement a major transformation of their mental health services systems, which will require ministries of health to generate policy for scale-up of government-funded trans-diagnostic community mental health care using the mhGAP. GMH researchers are charged with collaborating with governments to best inform how to help with this transformation.

\section{Acknowledgments}

The editors would like to thank Drs. Nakita Natala, Heidi Burns, and Daniel Wurzelmann for taking the time to review this manuscript.

\section{References}

Papers of particular interest, published recently, have been highlighted as:

- Of importance

•• Of major importance

1. Whiteford HA, Degenhardt L, Rehm J, Baxter AJ, Ferrari AJ, Erskine HE, et al. Global burden of disease attributable to mental and substance use disorders: findings from the global burden of disease study 2010. Lancet. 2013; 382:1575. [PubMed: 23993280]

2. Murray CJ, Vos T, Lozano R, Naghavi M, Flaxman AD, Michaud C, et al. Disability-adjusted life years (DALYs) for 291 diseases and injuries in 21 regions, 1990-2010: a systematic analysis for the global burden of disease study 2010. Lancet. 2013; 380(9859):2197-223. 
3. Kohn R, Saxena S, Levav I, Saraceno B. The treatment gap in mental health care. Bull World Health Organ. 2004; 82(11):858-66. [PubMed: 15640922]

4•. Bass JK, Annan J, McIvor Murray S, Kaysen D, Griffiths S, Cetinoglu T, et al. Controlled trial of psychotherapy for Congolese survivors of sexual violence. N Engl J Med. 2013; 368(23):218291. A randomized controlled trial in a conflict-affected region of the Democratic Republic of Congo showed the effectiveness of an adapted group cognitive processing therapy intervention delivered by community-based paraprofessionals for reducing anxiety and depression symptoms in adults. [PubMed: 23738545]

5. Rahman A, Malik A, Sikander S, Roberts C, Creed F. Cognitive behaviour therapy-based intervention by community health workers for mothers with depression and their infants in rural Pakistan: a cluster-randomised controlled trial. Lancet. 2008; 372(9642):902-9. [PubMed: 18790313]

6. Patel V, Weiss HA, Chowdhary N, Naik S, Pednekar S, Chatterjee S, et al. Effectiveness of an intervention led by lay health counsellors for depressive and anxiety disorders in primary care in Goa, India (MANAS): a cluster randomised controlled trial. Lancet. 2010; 376(9758):2086-95. [PubMed: 21159375]

7. Mehta N, Clement S, Marcus E, Stona A-C, Bezborodovs N, Evans-Lacko S, et al. Evidence for effective interventions to reduce mental health-related stigma and discrimination in the medium and long term: systematic review. Br J Psychiatry. 2015; 207(5):377-84. [PubMed: 26527664]

8. Fazel M, Hoagwood K, Stephan S, Ford T. Mental health interventions in schools in high-income countries. The Lancet Psychiatry. 2014; 1(5):377-87. [PubMed: 26114092]

9. Vieira MA, Gadelha AA, Moriyama TS, Bressan RA, Bordin IA. Evaluating the effectiveness of a training program that builds teachers' capability to identify and appropriately refer middle and high school students with mental health problems in Brazil: an exploratory study. BMC Public Health. 2014; 14(1):210. [PubMed: 24580750]

10. Lund C, Tomlinson M, De Silva M, Fekadu A, Shidhaye R, Jordans M, et al. PRIME: a programme to reduce the treatment gap for mental disorders in five low-and middle-income countries. PLoS Med. 2012; 9(12):e1001359. [PubMed: 23300387]

11. Hanlon C, Wondimagegn D, Alem A. Lessons learned in developing community mental health care in Africa. World Psychiatry. 2010; 9(3):185-9. [PubMed: 20975867]

12. Semrau M, Barley EA, Law A, Thornicroft G. Lessons learned in developing community mental health care in Europe. World Psychiatry. 2011; 10(3):217-25. [PubMed: 21991282]

13. Drake RE, Latimer E. Lessons learned in developing community mental health care in North America. World Psychiatry. 2012; 11(1):47-51. [PubMed: 22295009]

14• •. Chisholm D, Sweeny K, Sheehan P, Rasmussen B, Smit F, Cuijpers P, et al. Scaling-up treatment of depression and anxiety: a global return on investment analysis. The Lancet Psychiatry. 2016; 3(5):415-24. Return on investment analysis showed that returns to investment on scaling up effective treatment coverage for depression and anxiety disorders globally reults in benefit to cost ratios of up to 5.7 to 1 when the value of health returns is also included. [PubMed: 27083119]

15. Petersen I, Evans-Lacko S, Semrau M, Barry MM, Chisholm D, Gronholm P, et al. Promotion, prevention and protection: interventions at the population-and community-levels for mental, neurological and substance use disorders in low-and middle-income countries. Int J Ment Heal Syst. 2016; 10(1):1.

16. WHO. mhGAP intervention guide for mental, neurological and substance use disorders in nonspecialized health settings version 2.0. Geneva: World Health Organization; 2016.

17. Thornicroft G. Evidence-based mental health care and implementation science in low-and middleincome countries. Epidemiol Psychiatr Sci. 2012; 21(03):241-4. [PubMed: 22793882]

18. Collins PY, Pringle BA. Building a global mental health research workforce: perspectives from the National Institute of Mental Health. Acad Psychiatry. 2015; 40:1-4.

19. Saxena S, Saraceno B, Granstein J. Scaling up mental health care in resource-poor settings. Improving Mental Health Care: The Global Challenge. 2013:12-24.

20. Sweetland AC, Oquendo MA, Carlson C, Magidson JF, Wainberg ML. Mental health research in the global era: training the next generation. Acad Psychiatry. 2015; 40:1-6. 
21. Eaton J, McCay L, Semrau M, Chatterjee S, Baingana F, Araya R, et al. Scale up of services for mental health in low-income and middle-income countries. Lancet. 2011; 378(9802):1592-603. [PubMed: 22008429]

22. McGeorge P. Lessons learned in developing community mental health care in Australasia and the South Pacific. World Psychiatry. 2012; 11(2):129-32. [PubMed: 22654946]

23. Ito H, Setoya Y, Suzuki Y. Lessons learned in developing community mental health care in East and South East Asia. World Psychiatry. 2012; 11(3):186-90. [PubMed: 23024679]

24. Razzouk D, Gregório G, Antunes R, Mari JdJ. Lessons learned in developing community mental health care in Latin American and Caribbean countries. World Psychiatry. 2012; 11(3):191-5. [PubMed: 23024680]

25. Hanlon C, Luitel NP, Kathree T, Murhar V, Shrivasta S, Medhin G, et al. Challenges and opportunities for implementing integrated mental health care: a district level situation analysis from five low-and middle-income countries. PLoS One. 2014; 9(2):e88437. [PubMed: 24558389]

26. Collins PY, Patel V, Joestl SS, March D, Insel TR, Daar AS, et al. Grand challenges in global mental health. Nature. 2011; 475(7354):27-30. [PubMed: 21734685]

27. Petersen I, Lund C, Stein DJ. Optimizing mental health services in low-income and middle-income countries. Curr Opin Psychiatry. 2011; 24(4):318-23. [PubMed: 21546837]

28. Saxena S, Funk M, Chisholm D. World health assembly adopts comprehensive mental health action plan 2013-2020. Lancet. 2013; 381(9882):1970-1. [PubMed: 23746771]

29•. Lund C, Tomlinson M, Patel V. Integration of mental health into primary care in low-and middleincome countries: the PRIME mental healthcare plans. Br J Psychiatry. 2016; 208(s56):s1-3. A blueprint is given for developing and testing district mental health plans in low and middle income countries. [PubMed: 26447177]

30. Patel V, Belkin GS, Chockalingam A, Cooper J, Saxena S, Unützer J. Grand challenges: integrating mental health services into priority health care platforms. PLoS Med. 2013; 10(5):e1001448. [PubMed: 23737736]

31. Archer J, Bower P, Gilbody S, Lovell K, Richards D, Gask L, et al. Collaborative care for depression and anxiety problems. Cochrane Libr. 2012; 10:CD006525.

32. Hay JW, Katon WJ, Ell K, Lee P-J, Guterman JJ. Cost-effectiveness analysis of collaborative care management of major depression among low-income, predominantly Hispanics with diabetes. Value Health. 2012; 15(2):249-54. [PubMed: 22433755]

33. Mendenhall E, De Silva MJ, Hanlon C, Petersen I, Shidhaye R, Jordans M, et al. Acceptability and feasibility of using nonspecialist health workers to deliver mental health care: stakeholder perceptions from the PRIME district sites in Ethiopia, India, Nepal, South Africa, and Uganda. Soc Sci Med. 2014; 118:33-42. [PubMed: 25089962]

34. Ali G-C, Ryan G, De Silva MJ. Validated screening tools for common mental disorders in low and middle income countries: a systematic review. PLoS One. 2016; 11(6):e0156939. [PubMed: 27310297]

35. Ngo VK, Rubinstein A, Ganju V, Kanellis P, Loza N, Rabadan-Diehl C, et al. Grand challenges: integrating mental health care into the non-communicable disease agenda. PLoS Med. 2013; 10(5):e1001443. [PubMed: 23690753]

36. Kaaya S, Eustache E, Lapidos-Salaiz I, Musisi S, Psaros C, Wissow L. Grand challenges: improving HIV treatment outcomes by integrating interventions for co-morbid mental illness. PLoS Med. 2013; 10(5):e1001447. [PubMed: 23700389]

37. Fisher EB, Chan JC, Nan H, Sartorius N, Oldenburg B. Co-occurrence of diabetes and depression: conceptual considerations for an emerging global health challenge. J Affect Disord. 2012; 142:S56-66. [PubMed: 23062858]

38. Charlson FJ, Moran AE, Freedman G, Norman RE, Stapelberg NJ, Baxter AJ, et al. The contribution of major depression to the global burden of ischemic heart disease: a comparative risk assessment. BMC Med. 2013; 11(1):1. [PubMed: 23281898]

39. Nakash O, Levav I, Aguilar-Gaxiola S, Alonso J, Andrade LH, Angermeyer MC, et al. Comorbidity of common mental disorders with cancer and their treatment gap: findings from the world mental health surveys. Psychooncology. 2014; 23(1):40-51. [PubMed: 23983079] 
40. Parry CD, Patra J, Rehm J. Alcohol consumption and non-communicable diseases: epidemiology and policy implications. Addiction. 2011; 106(10):1718-24. [PubMed: 21819471]

41. Barnett K, Mercer SW, Norbury M, Watt G, Wyke S, Guthrie B. Epidemiology of multimorbidity and implications for health care, research, and medical education: a cross-sectional study. Lancet. 2012; 380(9836):37-43. [PubMed: 22579043]

42. Araya R, Alvarado R, Minoletti A. Chile: an ongoing mental health revolution. Lancet. 2009; 374(9690):597-8. [PubMed: 19699997]

43. Honikman S, van Heyningen T, Field S, Baron E, Tomlinson M. Stepped care for maternal mental health: a case study of the peri-natal mental health project in South Africa. PLoS Med. 2012; 9(5):e1001222. [PubMed: 22666181]

44. Rahman A, Surkan PJ, Cayetano CE, Rwagatare P, Dickson KE. Grand challenges: integrating maternal mental health into maternal and child health programmes. PLoS Med. 2013; 10(5):e1001442. [PubMed: 23667345]

45. Lora A, Kohn R, Levav I, McBain R, Morris J, Saxena S. Service availability and utilization and treatment gap for schizophrenic disorders: a survey in 50 low-and middle-income countries. Bull World Health Organ. 2012; 90(1):47-54B. [PubMed: 22271964]

46. Caqueo-Urízar A, Urzúa A, Jamett PR, Irarrazaval M. Objective and subjective burden in relatives of patients with schizophrenia and its influence on care relationships in Chile. Psychiatry Res. 2016; 237:361-5. [PubMed: 26809366]

47. Sweetland AC, Oquendo MA, Carlson C, Magidson JF, Wainberg ML. Mental health research in the global era: training the next generation. Acad Psychiatry. 2016; 40(4):715-20. [PubMed: 26497971]

48. Patel V. Universal health coverage for schizophrenia: a global mental health priority. Schizophr Bull. 2016; 42(4):885-90. [PubMed: 26245942]

49•. Brooke-Sumner C, Petersen I, Asher L, Mall S, Egbe CO, Lund C. Systematic review of feasibility and acceptability of psychosocial interventions for schizophrenia in low and middle income countries. BMC Psychiatry. 2015; 15:19. Preliminary evidence suggests acceptability of community-based psychosocial intervents for schizophrenia in LMICs, however well-designed interventions studies are need to provide evidence for overall feasibility. [PubMed: 25886524]

50. Asher L, De Silva M, Hanlon C, Weiss HA, Birhane R, Ejigu DA, et al. Community-based rehabilitation intervention for people with schizophrenia in Ethiopia (RISE): study protocol for a cluster randomised controlled trial. Trials. 2016; 17(1):299. [PubMed: 27342215]

51. Da Silva TFC, Lovisi G, Conover S, Susser E. Critical time intervention-task shifting (CTI-TS): a psychosocial intervention for people with severe mental illness in Latin America. Global Advanced Research Journal of Medicine and Medical Sciences. 2014; 3(5):087-9.

52. Farooq S. Early intervention for psychosis in low-and middle-income countries needs a public health approach. Br J Psychiatry. 2013; 202(3):168-9. [PubMed: 23457178]

53. Henderson C, Evans-Lacko S, Thornicroft G. Mental illness stigma, help seeking, and public health programs. Am J Public Health. 2013; 103(5):777-80. [PubMed: 23488489]

54- Thornicroft G, Mehta N, Clement S, Evans-Lacko S, Doherty M, Rose D, et al. Evidence for effective interventions to reduce mental-health-related stigma and discrimination. Lancet. 2016; 387(10023):1123-32. Social contact was found to be the most effective type of intervention to improve stigma-related knowledge and attitudes in the short term, but evidence for longer-term benefits is weak. [PubMed: 26410341]

55. de Girolamo G, Dagani J, Purcell R, Cocchi A, McGorry P. Age of onset of mental disorders and use of mental health services: needs, opportunities and obstacles. Epidemiol Psychiatr Sci. 2012; 21(01):47-57. [PubMed: 22670412]

56. Polanczyk GV, Salum GA, Sugaya LS, Caye A, Rohde LA. Annual research review: a metaanalysis of the worldwide prevalence of mental disorders in children and adolescents. J Child Psychol Psychiatry. 2015; 56(3):345-65. [PubMed: 25649325]

57. Klasen H, Crombag AC. What works where? A systematic review of child and adolescent mental health interventions for low and middle income countries. Soc Psychiatry Psychiatr Epidemiol. 2013; 48(4):595-611. [PubMed: 22961287] 
58•. Barry MM, Clarke AM, Jenkins R, Patel V. A systematic review of the effectiveness of mental health promotion interventions for young people in low and middle income countries. BMC Public Health. 2013; 13:835. Mental health promotion interventions for young people have been implemented effectively in LMIC school and community settings with moderate to strong evidence of their impact on positive and negative mental health outcomes, but evidence for interventions for younger children is lacking. [PubMed: 24025155]

59. Tomlinson M, Bornstein MH, Marlow M, Swartz L. Imbalances in the knowledge about infant mental health in rich and poor countries: too little progress in bridging the gap. Infant Ment Health J. 2014; 35(6):624-9. [PubMed: 25798511]

60. Kohrt BA, Yang M, Rai S, Bhardwaj A, Tol WA, Jordans MJ. Recruitment of child soldiers in Nepal: mental health status and risk factors for voluntary participation of youth in armed groups. Peace Confl. 2016; 22(3):208-16. [PubMed: 27524877]

61. O'Donnell K, Dorsey S, Gong W, Ostermann J, Whetten R, Cohen JA, et al. Treating maladaptive grief and posttraumatic stress symptoms in orphaned children in Tanzania: group-based traumafocused cognitive-behavioral therapy. J Trauma Stress. 2014; 27(6):664-71. [PubMed: 25418514]

62. McMullen J, O'Callaghan P, Shannon C, Black A, Eakin J. Group trauma-focused cognitivebehavioural therapy with former child soldiers and other war-affected boys in the DR Congo: a randomised controlled trial. J Child Psychol Psychiatry. 2013; 54(11):1231-41. [PubMed: 23738530]

63. Betancourt TS, Chambers DA. Optimizing an era of global mental health implementation science. JAMA psychiatry. 2016; 73(2):99-100. [PubMed: 26720304]

64. Abramsky T, Devries K, Kiss L, Nakuti J, Kyegombe N, Starmann E, et al. Findings from the SASA! Study: a cluster randomized controlled trial to assess the impact of a community mobilization intervention to prevent violence against women and reduce HIV risk in Kampala. Uganda BMC Med. 2014; 12(1):122. [PubMed: 25248996]

65. Veenema TG, Thornton CP, Corley A. The public health crisis of child sexual abuse in low and middle income countries: an integrative review of the literature. Int J Nurs Stud. 2015; 52(4):86481. [PubMed: 25557553]

66. Sumner SAMA, Saul J, et al. Prevalence of sexual violence against children and use of social services- seven countries, 2007-13. 2015

67. Kessler RC, McLaughlin KA, Green JG, Gruber MJ, Sampson NA, Zaslavsky AM, et al. Childhood adversities and adult psy-chopathology in the WHO world mental health surveys. $\mathrm{Br} \mathrm{J}$ Psychiatry. 2010; 197(5):378-85. [PubMed: 21037215]

68. Guedes A, Bott S, Garcia-Moreno C, Colombini M. Bridging the gaps: a global review of intersections of violence against women and violence against children. Global health action. 2016:9.

69. Whetten K, Shirey K, Pence BW, Yao J, Thielman N, Whetten R, et al. Trauma history and depression predict incomplete adherence to antiretroviral therapies in a low income country. PLoS One. 2013; 8(10):e74771. [PubMed: 24124455]

70. Patel V, Kieling C, Maulik PK, Divan G. Improving access to care for children with mental disorders: a global perspective. Arch Dis Child. 2013; 98(5):323-7. [PubMed: 23476001]

71. Weissman MM, Wickramaratne P, Gameroff MJ, Warner V, Pilowsky D, Kohad RG, et al. Offspring of depressed parents: 30 years later. Am J Psychiatr. 2016; 173:1024. [PubMed: 27113122]

72•. Herba CM, Glover V, Ramchandani PG, Rondon MB. Maternal depression and mental health in early childhood: an examination of underlying mechanisms in low-income and middle-income countries. The Lancet Psychiatry. 2016; 3:983. A biopsychosocial model is used to show that the mechanisms underlying associations between maternal depression and child mental health outcomes are impacted by the problematic context in which maternal depression occurs in LMICs. [PubMed: 27650772]

73. McDonnell CG, Valentino K. Intergenerational effects of childhood trauma evaluating pathways among maternal ACEs, perinatal depressive symptoms, and infant outcomes. Child maltreatment. 2016; 21(4):317-26. 
74. Siegenthaler E, Munder T, Egger M. Effect of preventive interventions in mentally ill parents on the mental health of the offspring: systematic review and meta-analysis. J Am Acad Child Adolesc Psychiatry. 2012; 51(1):8-17. e8. [PubMed: 22176935]

75. Gelaye B, Rondon MB, Araya R, Williams MA. Epidemiology of maternal depression, risk factors, and child outcomes in low-income and middle-income countries. The Lancet Psychiatry. 2016; 3(10):973-82. [PubMed: 27650773]

76• Rahman A, Fisher J, Bower P, Luchters S, Tran T, Yasamy T, et al. Interventions for common perinatal mental disorders in women in low-and middle-income countries: a systematic review and meta-analysis. Bull World Health Organ. 2013; 91(8):593-601. The pooled effect size for maternal depression was moderately strong in interventions delivered by trained community health workers in LMICs. [PubMed: 23940407]

77. Organization WH. Thinking healthy: a manual for psychosocial management of perinatal depression, WHO generic field-trial version 1.0. Vol. 2015. Geneva: World Health Organization; 2015.

78. Austin A, Herrick H, Proescholdbell S. Adverse childhood experiences related to poor adult health among lesbian, gay, and bisexual individuals. Am J Public Health. 2016; 106(2):314-20. [PubMed: 26691127]

79. Katz-Wise SL, Hyde JS. Victimization experiences of lesbian, gay, and bisexual individuals: a meta-analysis. J Sex Res. 2012; 49(2-3):142-67. [PubMed: 22380586]

80. Sullivan CG. Lesbian, gay, bisexual, and transgender health disparities are a global concern. Nurs Outlook. 2016; 64(3):279-80.

81. Hatzenbuehler ML, McLaughlin KA, Keyes KM, Hasin DS. The impact of institutional discrimination on psychiatric disorders in lesbian, gay, and bisexual populations: a prospective study. Am J Public Health. 2010; 100(3):452-9. [PubMed: 20075314]

82. Logie C. The case for the World Health Organization's commission on the social determinants of health to address sexual orientation. Am J Public Health. 2012; 102(7):1243-6. [PubMed: 22594723]

83. Blosnich JR, Farmer GW, Lee JG, Silenzio VM, Bowen DJ. Health inequalities among sexual minority adults: evidence from ten US states, 2010. Am J Prev Med. 2014; 46(4):337-49. [PubMed: 24650836]

84. Kates, J. The U.S. Government and global LGBT health: opportunities and challenges in the current era. Henry J. Kaiser Family Foundation; Menlo Park: 2014.

85. Nguyen TQ, Bandeen-Roche K, German D, Nguyen NT, Bass JK, Knowlton AR. Negative treatment by family as a predictor of depressive symptoms, life satisfaction, suicidality, and tobacco/alcohol use in Vietnamese sexual minority women. LGBT health. 2016; 3:357. [PubMed: 27219025]

86. Hughes TL, Wilsnack SC, Kantor LW. The influence of gender and sexual orientation on alcohol use and alcohol-related problems: toward a global perspective. Alcohol Res. 2016; 38(1):121. [PubMed: 27159819]

87. Kakuma R, Minas H, van Ginneken N, Dal Poz MR, Desiraju K, Morris JE, et al. Human resources for mental health care: current situation and strategies for action. Lancet. 2011; 378(9803):165463. [PubMed: 22008420]

88. Bruckner TA, Scheffler RM, Shen G, Yoon J, Chisholm D, Morris J, et al. The mental health workforce gap in low-and middle-income countries: a needs-based approach. Bull World Health Organ. 2011; 89(3):184-94. [PubMed: 21379414]

89. Patel V, Weiss HA, Chowdhary N, Naik S, Pednekar S, Chatterjee S, et al. Lay health worker led intervention for depressive and anxiety disorders in India: impact on clinical and disability outcomes over 12 months. Br J Psychiatry. 2011; 199(6):459-66. [PubMed: 22130747]

90. Kazdin AE, Rabbitt SM. Novel models for delivering mental health services and reducing the burdens of mental illness. Clin Psychol Sci. 2013; doi: 10.1177/2167702612463566

91. Petersen I, Lund C, Bhana A, Flisher AJ. A task shifting approach to primary mental health care for adults in South Africa: human resource requirements and costs for rural settings. Health Policy Plan. 2012; 27(1):42-51. [PubMed: 21325270] 
92. Buttorff C, Hock RS, Weiss HA, Naik S, Araya R, Kirkwood BR, et al. Economic evaluation of a task-shifting intervention for common mental disorders in India. Bull World Health Organ. 2012; 90(11):813-21. [PubMed: 23226893]

93. Bolton P, Bass J, Betancourt T, Speelman L, Onyango G, Clougherty KF, et al. Interventions for depression symptoms among adolescent survivors of war and displacement in northern Uganda: a randomized controlled trial. JAMA. 2007 Aug 1; 298(5):519-27. [PubMed: 17666672]

94••. Becker AE, Kleinman A. Mental health and the global agenda. N Engl J Med. 2013; 369(1):6673. An outline is given for how to reduce the mental health treatment gap by building clinical capacity, developing new models of treatment, creating a focused and relevant research agenda, and overcoming barriers to equitable care. [PubMed: 23822778]

95••. Joshi R, Alim M, Kengne AP, Jan S, Maulik PK, Peiris D, et al. Task shifting for noncommunicable disease management in low and middle income countries-a systematic review. PLoS One. 2014; 9(8):e103754. A review shows preliminary evidence of the effectiveness and affordability of the use of non-physician health care workers for improving access to healthcare for non-communicable diseases, including mental health, however, such programs need to be accompanied by health system re-structuring, and additional high-quality studies are required to support preliminary evidence. [PubMed: 25121789]

96. Fricchione GL, Borba CP, Alem A, Shibre T, Carney JR, Henderson DC. Capacity building in global mental health: professional training. Harv Rev Psychiatry. 2012; 20(1):47-57. [PubMed: 22335182]

97. Thornicroft G, Cooper S, Bortel TV, Kakuma R, Lund C. Capacity building in global mental health research. Harv Rev Psychiatry. 2012; 20(1):13-24. [PubMed: 22335179]

98••. Meffert SM, Neylan TC, Chambers DA, Verdeli H. Novel implementation research designs for scaling up global mental health care: overcoming translational challenges to address the world's leading cause of disability. Int J Ment Health Syst. 2016; 10:19. A new type of implementation science study design, effectiveness-implementation hybrids, are proposed to speed the translation and scale up of mental health care in LMICs. [PubMed: 26958075]

99. Murray LK, Tol W, Jordans M, Sabir G, Amin AM, Bolton P, et al. Dissemination and implementation of evidence based, mental health interventions in post conflict, low resource settings. Intervention. 2014; 12:94-112. [PubMed: 28316559]

100. Stuart H. Reducing the stigma of mental illness. Global Mental Health. 2016; 3:e17. [PubMed: 28596886]

101. Shidhaye R, Kermode M. Stigma and discrimination as a barrier to mental health service utilization in India. International health. 2013; 5(1):6-8. [PubMed: 24029838]

102. Semrau M, Evans-Lacko S, Koschorke M, Ashenafi L, Thornicroft G. Stigma and discrimination related to mental illness in low-and middle-income countries. Epidemiol Psychiatr Sci. 2015; 24(05):382-94. [PubMed: 25937022]

103. Cuijpers P, Beekman AT, Reynolds CF. Preventing depression: a global priority. JAMA. 2012; 307(10):1033-4. [PubMed: 22416097]

104. Chisholm D, Saxena S. Cost effectiveness of strategies to combat neuropsychiatric conditions in sub-Saharan Africa and South East Asia: mathematical modelling study. BMJ. 2012; 344:e609. [PubMed: 22389339]

105••. Chisholm D, Burman-Roy S, Fekadu A, Kathree T, Kizza D, Luitel NP, et al. Estimating the cost of implementing district mental healthcare plans in five low-and middle-income countries: the PRIME study. Br J Psychiatry. 2016; 208(s56):s71-s8. The cost of scaling up mental health services in four LMICs ranged from US $\$ 0.21$ to 0.56 per person; in the higher income context of South Africa, it was US\$1.86), and in all countries, the additional amount needed each year to reach target coverage goals after 10 years was below $\$ 0.10$ per person. [PubMed: 26447170] 